\title{
Dehydration of protein lactoferrin-glycomacropeptide nanohydrogels
}

\author{
Ana I. Bourbon $^{\mathrm{a}, *}$, Letricia Barbosa-Pereira ${ }^{\mathrm{b}}$, António A. Vicente ${ }^{\mathrm{c}}$, Miguel A. Cerqueira ${ }^{\mathrm{a}}$, \\ Lorenzo Pastrana ${ }^{\text {a }}$
}

${ }^{a}$ INL - International Iberian Nanotechnology Laboratory, Av. Mestre José Veiga S/n, 4715-330, Braga, Portugal

${ }^{\mathrm{b}}$ Department of Agricultural Forest and Food Sciences, University of Turin, Largo Braccini 2, Grugliasco, Turin, Italy

${ }^{\mathrm{c}}$ CEB -Centre of Biological Engineering, University of Minho, 4710-057, Braga, Portugal

\section{A B S T R A C T}

Protein based nanohydrogels have recently gained interest due their high ability to carry and deliver active compounds. However, one of the limitations of using protein-based systems is their high sensitivity to physicochemical stresses during processing and storage. Protein-based formulations are commonly prepared as solid dosage forms once their stability can be achieved in the solid rather than in the liquid state. One of the methods to improve the stability of protein-based systems is drying, being freeze and spray drying the most popular methods. Nanohydrogels composed of lactoferrin and glycomacropeptide were developed by thermal gelation and dried using a freeze-dryer (CHRIST - Alpha 1-4 LD plus, Germany) and a nano spray dryer B-90 (BÜCHI Labortechnik AG, Switzerland). For nano spray-drying different experimental conditions were tested such as: the inlet temperature $\left(80,100\right.$ and $\left.120^{\circ} \mathrm{C}\right)$ and the hole size of the vibrating membrane in the spray cap $(4 \mu \mathrm{m}$ and $7 \mu \mathrm{m}$ ), while for freeze drying the nanohydrogels where maintained at $-40{ }^{\circ} \mathrm{C}$ for a drying period of about $24 \mathrm{~h}$. The physicochemical properties of the resulting dried nanohydrogels were compared through different techniques: differential scanning calorimetry (DSC), thermogravimetry (TGA), X-ray diffraction (XRD) and scanning electron microscopy (SEM). DSC shows an endothermic peak ranging from 82 to $90{ }^{\circ} \mathrm{C}$, indicating that during the drying methodologies the second denaturation peak of lactoferrin (around $90^{\circ} \mathrm{C}$ ) is maintained. No significant differences $(\mathrm{p}<0.05)$ for denaturation peak temperatures were observed when different inlet temperatures or spray cap size were applied during the nano spray-drying conditions. When compared with freeze-drying it is possible to observe that a denaturation peak around the same range of temperatures was detected, also indicating that this drying process did not affect the denaturation of the protein. XRD results of nanohydrogels dried by freeze-drying revealed that crystallinity is significantly higher when compared with spray-dried nanohydrogels, explaining the lower thermal degradation observed in TGA for freeze-dried nanohydrogels. Nanohydrogels morphology after the drying process was evaluated by SEM. Nanohydrogels obtained by nano spray dryer B-90 allowed identifying the presence of particles with spherical shape, while nanohydrogels obtained by freeze drying had a sponge-like appearance. This work shows the influence of the drying process of protein-based nanohydrogels in their physical-chemical properties, thus pointing at which will be the preferred technology to be used in a future industrial application.

\section{Introduction}

Proteins are interesting biopolymers to produce micro and nanoscale delivery systems. Their ability to interact with lipophilic or hydrophilic compounds is a powerful tool to encapsulate active molecules and protect them against oxidative processes or improve their stability, bioaccessibility and add nutritional value. However, proteins are high sensitive to environmental conditions (temperature, $\mathrm{pH}$, moisture) during processing and storage processes. In order to avoid this limitation, protein-based formulations are commonly prepared as solid dosage forms to improve their stability (Ameri \& Maa, 2006). One of the methods to improve the stability of protein based systems, is drying, being freeze and spray drying the most popular methods (Maltesen \& van de Weert, 2008).

Freeze drying is the process of removing water from a product by freezing it then subliming the ice to vapour (Garcia-Amezquita, Welti-Chanes, Vergara-Balderas, \& Bermúdez-Aguirre, 2016). This process consists on three steps: the first is freezing, which involves freezing the system and create a solid matrix suitable for drying. The second stage is drying to remove the ice through sublimation, which is done by reducing the pressure of the system while maintains the system temperature. The final step is called secondary drying, in which bound water is removed until the residual moisture (Garcia-Amezquita et al., 2016). Several works indicate that protein denaturation during the formation of ice crystals can be a relevant factor changing the protein structure (Garcia-Amezquita et al., 2016). Optimization of the freezing process should therefore take the effect of the ice surface area into account since it can contribute to freeze-induced protein denaturation. Furthermore this method is considered expensive with low capacity (Maltesen \& van de Weert, 2008).

\footnotetext{
* Corresponding author.

E-mail address: ana.bourbon@inl.int (A.I. Bourbon).
} 
Compared to freeze drying, spray drying is a faster and more economical, single step, drying method which can be designed as a continuous drying process (Lee, Heng, Ng, Chan, \& Tan, 2011). Spray drying has been identified as a suitable method for the preparation of dried proteins. It offers the advantage of drying and particle formation in a single-step continuous and scalable process with particle engineering possibilities (Lee et al., 2011). Furthermore, various particle properties such as particle size, bulk density and flow properties can easily be tuned via simple manipulation of the process parameters or spray dryer configuration. During spray drying process a liquid feedstock is atomized into a spray of fine droplets and then brought into contact with the hot drying gas at sufficient temperature for the moisture evaporation to take place. As the moisture evaporates from the droplets, the solid product is formed, and the powder is readily recovered from the drying gas (Dyvelkov \& Sloth, 2014). This technique allows that the rapid evaporation of solvents (water) during the drying process keeps the droplet temperature low and is possible to produce encapsulated systems with heat sensitive. (Arpagaus et al., 2018; Arpagaus, 2019a).

The optimum choice of drying technique will depend mainly on the economics of drying and on the intended route of drug administration, but also is important to know the formulation used and the protein structure.

Recently, a new spray-dryer equipment was developed by BÜCHI Labortechnik AG, which resulted in high particle recovery rates up to milligram sample amounts of powder particles with particle sizes between $300 \mathrm{~nm}$ and $5 \mu \mathrm{m}$, showing a high potential to development of nano sized protein formulations (Arpagaus, 2012; Arpagaus, 2019a). The nano spray dryer B-90 has a vibration at ultrasonic frequency which allows to obtain a fine and homogeneous droplets (Arpagaus, 2019b). Protein nanohydrogels composed by a mixture of lactoferrin (Lf) and glycomacropeptide (Gmp) were developed by thermal gelation in a previous work (Bourbon et al., 2015). Lf is an iron-binding glycoprotein and can be found in various biological fluids of mammals (Bokkhim, Bansal, Grøndahl, \& Bhandari, 2016). The iron binding ability along with its cationic nature is responsible for a diverse range of physiological functions such as antimicrobial, anti-inflammatory, immunomodulatory and anti-carcinogenic (Sheehy et al., 2008). Gmp is a glycosylated phosphate peptide derived from k-casein and attracted widespread attention in the fields of functional food research and health care due their bioactive properties such as the ability to neutralize enterotoxin, inhibit virus or bacterial adhesion to cells, inhibit gastrointestinal secretions and ability to regulate immune system (Arpagaus, 2012; Neelima, Sharma, Rajput, \& Mann, 2013; Thomä-Worringer, Sørensen, \& López-Fandiño, 2006). The interesting properties and stability of the developed nanohydrogels in an aqueous solutions (Bourbon et al., 2015; Bourbon, Cerqueira, \& Vicente, 2016) lead to the need in the evaluation of techniques to dry the nanohydrogels without changing their main properties, aiming their stability and further rehydration. Based on this, the main goal of this work is dehydrate protein-based nanohydrogels, using two different drying methods: freeze and spray drying and evaluate their physic-chemical properties after drying.

\section{Materials and methods}

\subsection{Preparation of lactoferrin-glycomacropeptide nanohydrogels}

Nanohydrogels were prepared as described in Bourbon et al. (2015). Briefly, $2.5 \mu \mathrm{M}$ of Lactoferrin-Lf (DMV International, USA) and $8.33 \mu \mathrm{M}$ of Glycomacropeptide-GMP (Davisco Food International, INC., USA) were dissolved separately, in deionized water purified to a resistance of $15 \mathrm{M} \Omega$ (Millipore, France) at $25{ }^{\circ} \mathrm{C}$. The $\mathrm{pH}$ values of biopolymer solutions were separately adjusted to 5 , with 0.1 mol.L $\mathrm{L}^{-1}$ of hydrochloric acid (Panreac, Spain). Lf aqueous solution was added dropwise into GMP aqueous solution with gentle stirring until a final molar ratio of 1:7 (Lf: GMP) was reached. After gentle stirring for $30 \mathrm{~min}$, the mixture of Lf-GMP was subsequently heated at $80{ }^{\circ} \mathrm{C}$ for $20 \mathrm{~min}$ in a water bath (closed system) to obtain a homogeneously dispersed nanohydrogel.

\subsection{Dehydration of nanohydrogels}

\subsubsection{Freeze drying}

Nanohydrogels solution was first frozen for $24 \mathrm{~h}$ at $-20^{\circ} \mathrm{C}$, after this period the samples are frozen until $-80{ }^{\circ} \mathrm{C}$ during $24 \mathrm{~h}$. Freeze drying was carried out in a pilot scale freeze dryer (CHRIST - Alpha 1-4 LD plus, Germany). The freeze drying operation temperature was maintained at $-40{ }^{\circ} \mathrm{C}$ for a drying period about $24 \mathrm{~h}$. Nanohydrogels powders obtained were stored at $20^{\circ} \mathrm{C}$ (controlled by laboratory air conditioning system) and $0 \% \mathrm{RH}$ (obtained by equilibration in a desiccator with a saturated salt, under vacuum), until further use.

\subsubsection{Nano spray drying}

Nanohydrogels were dried using a Nano Spray Dryer B-90 (BÜCHI Labortechnik AG, Flawil, Switzerland). This spray dryer has a vibrating membrane in the spray cap to atomize the feed and the particles are collected by an electrostatic particle colector. The controllable parameters are the inlet temperature $\mathrm{T}_{\mathrm{in}}$, the hole size of the vibrating membrane in the spray cap, the flow rate of the drying gas as well as the relative spray rate. The $T_{\text {in }}$ applied to samples was: 80,100 and $120^{\circ} \mathrm{C}$ for the spray cap size of $4 \mu \mathrm{m}$ and $7 \mu \mathrm{m}$. Compressed air was used as the drying gas and the flow rate was set to about $100 \mathrm{~L} \mathrm{~min} \operatorname{mor}^{-1}$ or $110 \mathrm{~L}$ $\min ^{-1}$. The relative spray rate was set to $100 \%$ for most of the runs but had to be reduced for certain experiments, in order to obtain a reasonably dry product in the collector. Nanohydrogels powders obtained were stored at $20{ }^{\circ} \mathrm{C}$ (controlled by laboratory air conditioning system) and $0 \% \mathrm{RH}$ (obtained by equilibration in a desiccator with a saturated salt, under vacuum), until further use.

\subsection{Differential scanning calorimetry and thermogravimetric analyses}

Differential scanning calorimetry (DSC) measurements were performed in a TG-DSC Setsys evolution 16/18 (Setaram). Approximately $10 \mathrm{mg}$ of the sample was placed in aluminium DSC pans (Al crimp Pan C.201-52943). The measurements were performed between $25^{\circ} \mathrm{C}$ and $150{ }^{\circ} \mathrm{C}$ at a heating rate of $10^{\circ} \mathrm{C} \cdot \mathrm{min}^{-1}$ under a nitrogen atmosphere.

Thermogravimetric analyses (TGA) were completed with a Shimadzu TGA-50 (Shimadzu Corporation, Kyoto, Japan). Samples were placed in the balance system and heated from 25 to $600{ }^{\circ} \mathrm{C}$ at a heating rate of 10 ${ }^{\circ} \mathrm{C} . \mathrm{min}^{-1}$ under a nitrogen atmosphere. For each measurement, at least two repetitions were made for each type of film.

\subsection{Fourier transform infrared spectroscopy}

Fourier transform infrared (FTIR) spectra of the films were recorded with a PerkinElmer 16 PC (Boston, USA) FTIR spectrometer in the wavelength range 4000 to $400 \mathrm{~cm}^{-1}$ at a resolution of $4 \mathrm{~cm}^{-1}$. The absorbance of each FTIR spectrum was normalized between 0 and 1 . The measurements were performed in triplicate, using attenuated total reflection mode.

\subsection{Wide angle $X$-ray diffraction analysis}

Wide angle X-ray diffraction (WAXD) spectra of film samples were recorded with a Bruker D8 Discover diffractometer (lambda source of $0.154 \mathrm{~nm}$ ). The scanning range was from $2 \theta=10-60^{\circ}$.

\subsection{Scanning electron microscope}

Nanohydrogels morphology was examined using scanning electron microscopy (Nova NanoSEM 200, Netherlands) with an accelerating voltage from 10 to $211 \mathrm{KV}$. Before analyses, all samples were mounted on aluminium stubs using carbon adhesive tape and sputter-coated with gold (thickness of about $10 \mathrm{~nm}$ ). 


\subsection{Size distribution}

Nanohydrogels were characterized in terms of size distribution (by intensity) using a Dynamic Light Scattering (DLS) apparatus (Zetasizer Nano ZS, Malvern Instruments, UK). All measurements were performed at $25{ }^{\circ} \mathrm{C}$. The results are given as the average \pm standard deviation of nine measurements.

Size distribution was evaluated based on the speed at which the particles are diffusing due to Brownian motion. This is done by measuring the rate at which the intensity of the scattered light fluctuates when detected using a suitable optical arrangement. Particle size of particles is calculated based on Stokes-Einstein equation n (Equation (1)):

$d(H)=\frac{K T}{3 \pi D}$

Where $d(H)$ is the hydrodynamic diameter of particles, $K$ is the Boltzmann constant, $T$ is the temperature in Kelvin (K), $D$ is the translational diffusion coefficient and $\eta$ is the medium viscosity (Malvern, 2005).

\subsection{Nanohydrogels rehydration}

Dried nanohydrogels obtained by freeze and spray drying were rehydrated in deionized water. $10 \mathrm{mg}$ of protein nanohydrogels were dissolved in $10 \mathrm{ml}$ of deionized water at $25{ }^{\circ} \mathrm{C}$ for $12 \mathrm{~h}$ with gentle stirring.

\subsection{Statistical analysis}

The analytical values were taken using three independent determinations. The obtained values were expressed as mean values \pm standard errors of three independent determinations. As for the statistical analysis, they were conducted using a statistical software program SigmaPlot 11.0 (free trial).

\section{Results and discussion}

\subsection{Thermal analysis}

Evaluating the denaturation level of proteins' structure is extremely relevant to determine and measure their functionality. Differential scanning calorimetry can be used to evaluate the thermal transitions in proteins and access the effect of different drying methods on protein denaturation. The water content affects both denaturation temperature and heat of transition of proteins (Ghribi et al., 2015). Being so, the magnitude of changes in the thermal properties caused by the drying process on protein properties was studied by DSC (Fig. 1). The peak denaturation $\left(T_{d}\right)$ and heat of transition or enthalpy change $(\Delta H)$ values are presented in Table 1.
During the thermal scans from 25 to $150{ }^{\circ} \mathrm{C}$, an endothermic peak was observed for the dried samples with a peak denaturation temperature ranging from 82 to $90^{\circ} \mathrm{C}$. Different authors reported the presence of two denaturation temperatures for Lf by DSC measurements, the first denaturation temperature, around $60{ }^{\circ} \mathrm{C}$, corresponds to apo-lactoferrin and second denaturation temperature, around $90{ }^{\circ} \mathrm{C}$, corresponds to holo-lactoferrin (Bengoechea, Peinado, \& McClements, 2011; Bokkhim, Bansal, Grøndahl, \& Bhandari, 2013; Brisson, Britten, \& Pouliot, 2007; González-Chávez, Arévalo-Gallegos, \& Rascón-Cruz, 2009). The results showed that the denaturation temperature referring to holo-lactoferrin is maintained indicating that the methodology to produce nanohydrogels (a temperature of $80^{\circ} \mathrm{C}$ during $20 \mathrm{~min}$ is used) did not affect the total denaturation of globular protein, but, and as expected, the denaturation of the apo-lactoferrin happens during the thermal treatment needed for the nanohydrogel production. Due to the random coil structure of GMP and to the absence of disulfide bonds, no denaturation peaks were reported for GMP (Farías, Martinez, \& Pilosof, 2010). However, further research would be needed to evaluate the effect of interaction between GMP and Lf on thermal transitions of nanohydrogels.

During the drying process of the nanohydrogels using nano spray drying the second denaturation peak was maintained and no significant differences $(p<0.05)$ for denaturation peaks were observed when different inlet temperatures or spray cap sizes were used during the process. When compared with freeze-drying it is possible to observe that a denaturation peak happens in the same range of temperatures, also indicating that this drying process did not affect the denaturation of the protein.

The value of $\Delta H$ can be used to evaluate the proportion of the protein

Table 1

Peak denaturation $\left(\mathrm{T}_{\mathrm{d}}\right)$ and heat of transition or enthalpy $(\Delta \mathrm{H})$ obtained by differential scanning calorimetry (DSC) for nanohydrogels dried by freeze and spray drying.

\begin{tabular}{|c|c|c|c|c|}
\hline \multicolumn{5}{|l|}{ Sample } \\
\hline $\begin{array}{l}\text { Drying } \\
\text { methodology }\end{array}$ & $\begin{array}{l}\text { Spray cap size } \\
(\mu \mathrm{m})\end{array}$ & $\begin{array}{l}\mathrm{T}_{\text {in }} \\
\left({ }^{\circ} \mathrm{C}\right)\end{array}$ & $\mathrm{T}_{\mathrm{d}}\left({ }^{\circ} \mathrm{C}\right)$ & $\Delta \mathrm{H}\left(\mathrm{J} . \mathrm{g}^{-1}\right)$ \\
\hline \multirow[t]{6}{*}{ Spray-drying } & 4 & 80 & $86.3 \pm 1.2^{\mathrm{a}}$ & $30.8 \pm 3.5^{\mathrm{a}}$ \\
\hline & & 100 & $84.4 \pm 0.6^{a}$ & $29.9 \pm 4.3^{\mathrm{a}}$ \\
\hline & & 120 & $\begin{array}{l}85.80 \pm \\
0.4^{\mathrm{a}}\end{array}$ & $34.8 \pm 3.9^{\mathrm{a}}$ \\
\hline & 7 & 80 & $82.1 \pm 2.6^{\mathrm{a}}$ & $30.8 \pm 3.8^{\mathrm{a}}$ \\
\hline & & 100 & $86.7 \pm 1.5^{\mathrm{a}}$ & $33.5 \pm 3.5^{\mathrm{a}}$ \\
\hline & & 120 & $85.1 \pm 1.6^{\mathrm{a}}$ & $32.7 \pm 4.2^{\mathrm{a}}$ \\
\hline Freeze-drying & - & - & $84.4 \pm 1.3^{\mathrm{a}}$ & $\begin{array}{l}220.9 \pm \\
3.7^{\mathrm{b}}\end{array}$ \\
\hline
\end{tabular}

All the data are expressed as mean $\pm \mathrm{SD}$ and are the mean of three replicates. Means with different superscript letters within the same column are significantly different $(p<0.05)$.

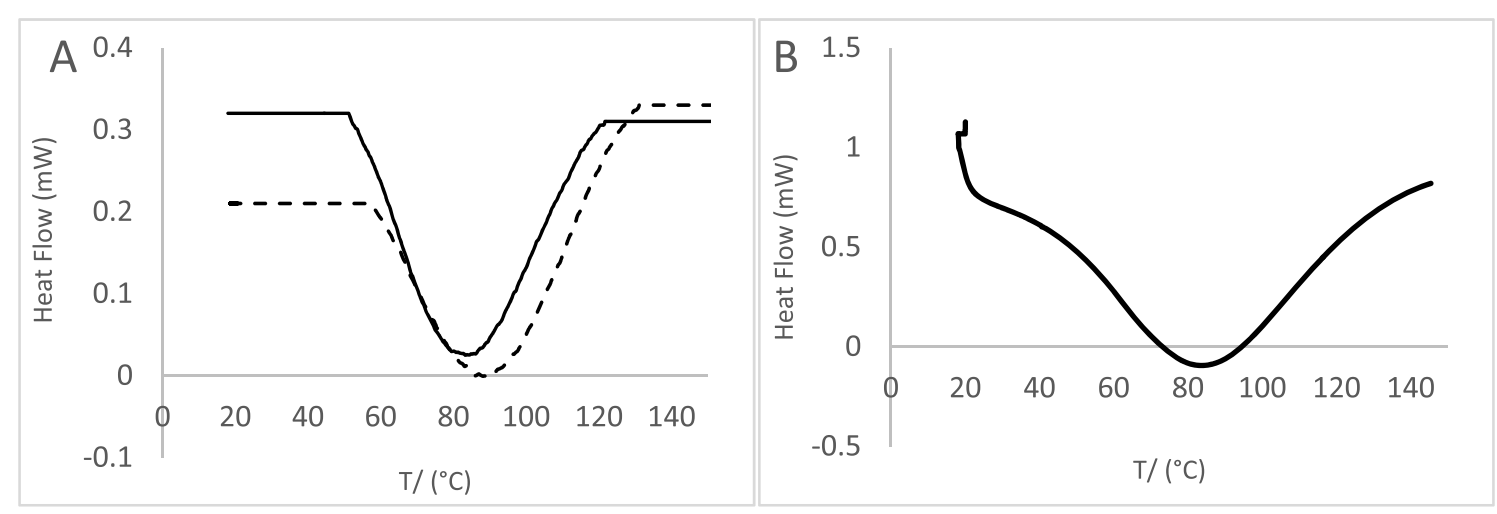

Fig. 1. DSC scans of: A) spray-dried nanohydrogels with a $\mathrm{T}_{\mathrm{in}}$ of $80^{\circ} \mathrm{C}$ with a spray cap size of $4 \mu \mathrm{m}(-$-) and $7 \mu \mathrm{m}()$ and B) freeze-dried nanohydrogels. 


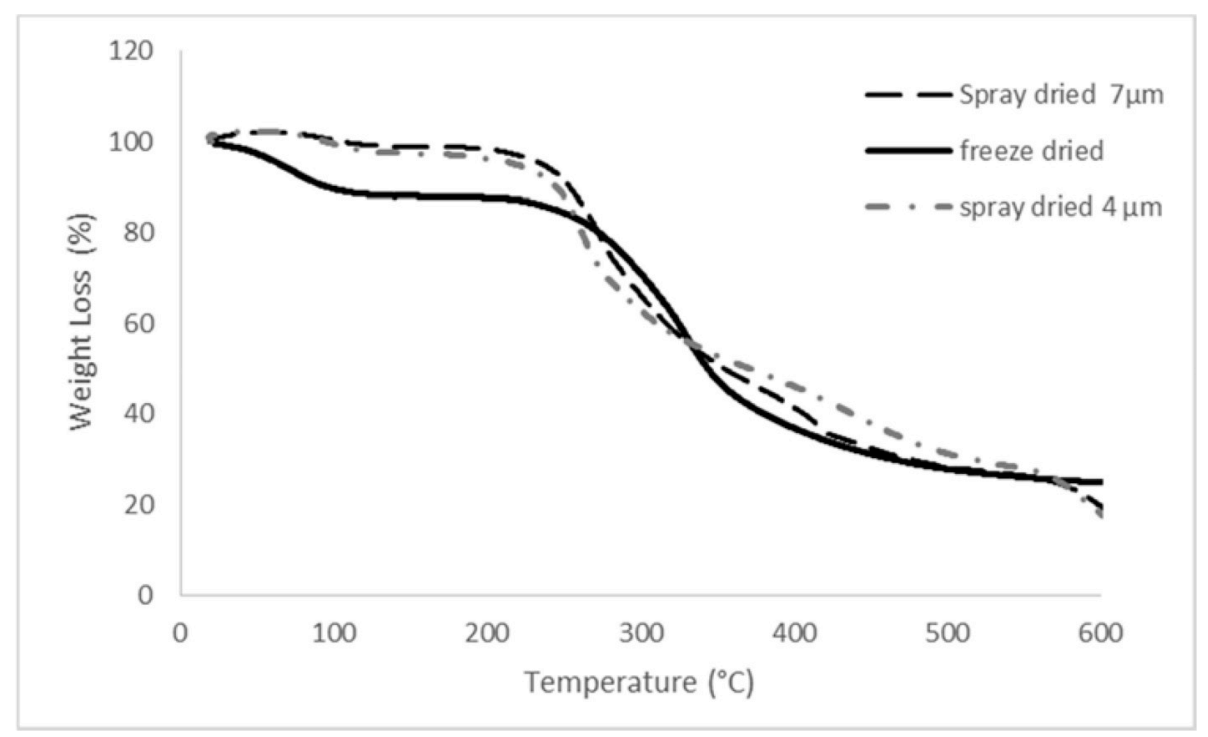

Fig. 2. Thermogravimetric analysis of nanohydrogels; dried by spray-drying at 120 and dried by freeze-drying.

that was denatures during the thermal process, reflecting the status of ordered conformation of food proteins (Ghribi et al., 2015). The lower value observed for spray-dried nanohydrogels, comparing to freeze drying, is attributed to the less ordered structure of the protein obtained in that case. During drying with convective air, many of the intermolecular bonds were disrupted and the protein structure was (partially) lost, which lead to a decrease of the energy required for complete denaturation (Ghribi et al., 2015). These results give the indication that the spray drying process leads to a high denaturation of the nanohydrogels when compared with the freeze drying.

Thermogravimetric analysis provided information about the weight loss profile for nanohydrogels dried at different conditions. Table 2 presents the information regarding the thermal events of the samples and Fig. 2 shows the thermal profile of nanohydrogels dried by spraydrying ( $\mathrm{T}_{\text {in }}$ of $120^{\circ} \mathrm{C}$ with a spray cap size of $4 \mu \mathrm{m}$ and $7 \mu \mathrm{m}$ ) and by freeze-drying.

TGA of dried nanohydrogels showed two major thermal degradation events occurring between 20 and $125^{\circ} \mathrm{C}$ and between 150 and $300{ }^{\circ} \mathrm{C}$. At around $120^{\circ} \mathrm{C}$, there was some mass loss which can be attributed to the moisture evaporation. The second major weight loss happens

Table 2

Weight loss obtained by thermogravimetric analysis for nanohydrogels dried by freeze and spray drying.

\begin{tabular}{lllll}
\hline Sample & & & & \\
\hline $\begin{array}{l}\text { Drying } \\
\text { method }\end{array}$ & Spray Cap size $(\mu \mathrm{m})$ & $\mathrm{T}_{\text {in }}\left({ }^{\circ} \mathrm{C}\right)$ & $\mathrm{T}\left({ }^{\circ} \mathrm{C}\right)$ & Weight loss $(\%)$ \\
\hline Spray-drying & 4 & & & \\
& & 80 & 125 & 4.27 \\
& & 280 & 40.25 \\
& & 100 & 125 & 6.27 \\
& & 250 & 42.21 \\
& & 120 & 125 & 4.09 \\
& & & 280 & 43.33 \\
& & 80 & 125 & 4.91 \\
& & 260 & 44.55 \\
& & 100 & 285 & 4.77 \\
& & 120 & 125 & 4.08 \\
& & & 280 & 51.93 \\
Freeze-drying & - & - & 110 & 5.06 \\
& & & 320 & 28.03 \\
\hline
\end{tabular}

$\mathrm{T}_{\mathrm{in}}$ - inlet temperature used in nano spray drying.

$\mathrm{T}$ - Temperature of the thermal event. between 150 and $300{ }^{\circ} \mathrm{C}$ and is possibly due to the protein degradation. Similar results were also observed for milk proteins (Hundre, Karthik, \& Anandharamakrishnan, 2015). A lower loss of mass (Table 2) was observed in the second event for freeze-dried nanohydrogels when compared with spray-dried samples indicating a better stability of the nanohydrogels to higher temperatures. During the thermal degradation, it was observed that increasing the drying temperature of nano spray dryer B-90, occurred an increase of protein degradation, from $20.81 \pm$ $1.21 \%, 24.91 \pm 3.21 \%$ and $35.57 \pm 1.65 \%$ for $80^{\circ} \mathrm{C} .100{ }^{\circ} \mathrm{C}$ and $120^{\circ} \mathrm{C}$, respectively. When compared with freeze dried samples, only $19.49 \pm$ $2.11 \%$ of freeze dried nanohydrogels were thermal degraded. These results suggest that the selection of drying temperature on nano spray dryer B-90 can have an effect on protein degradation.

\subsection{X-ray diffraction and FTIR spectroscopy}

Food materials in solid state may be crystalline, semi-crystalline or amorphous. XRD was performed to confirm the state of the structure of nanohydrogels samples. Fig. 3 shows XRD patterns of nanohydrogels dried by spray- and freeze-drying, revealing a dominant amorphous phase. Nanohydrogels dried at different conditions by spray-drying revealed similar XRD patterns (results not shown) indicating that $T_{\text {in }}$ and the size of cap used did not affect the solid state of samples. In order to better compare the differences between the two drying methods used, an example of XRD results for nanohydrogels dried by spray drying is also reported in Fig. 3.

Nanohydrogels dried by freeze-drying revealed the presence of a broad band with a maximum at $2 \theta=20^{\circ}$, as also reported for chickpea protein concentrates, where as an amorphous halo was detected at the same $2 \theta$ value (Ghribi et al., 2015). Moreover, freeze-dried samples also revealed the presence of small peaks around $2 \theta=30^{\circ}$, indicating that there is a combination of crystalline and amorphous regions. The freeze-drying process lead to the formation of a crystalline structure during the drying process that was presented as one of the effects of freeze-drying to proteins. Different works revealed that crystalline powders are more stable against denaturation treatments and during storage than the amorphous proteins (Ghribi et al., 2015). This result can explain the lower thermal degradation observed by TGA measurements for freeze-dried nanohydrogels, the crystallinity of which is significantly higher when compared with that of spray-dried nanohydrogels.

FTIR was used to evaluate the influence of drying process in chemical 


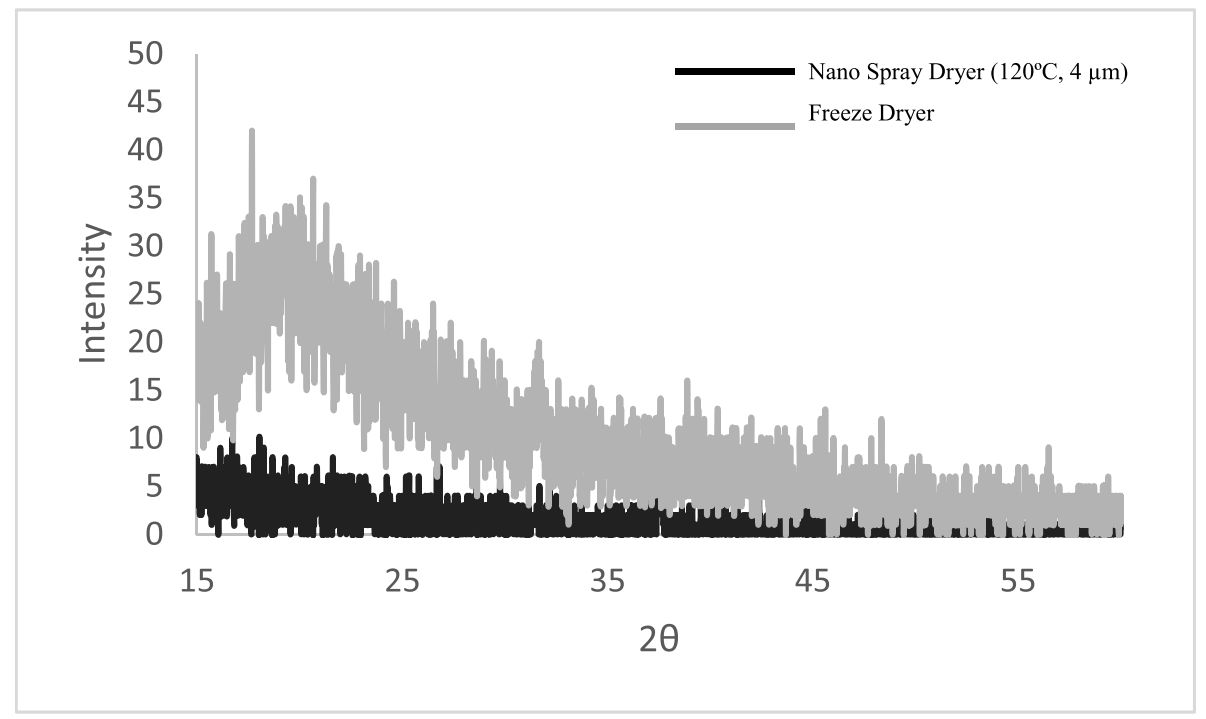

Fig. 3. XRD patterns of nanohydrogels dried by spray-drying by freeze-drying.

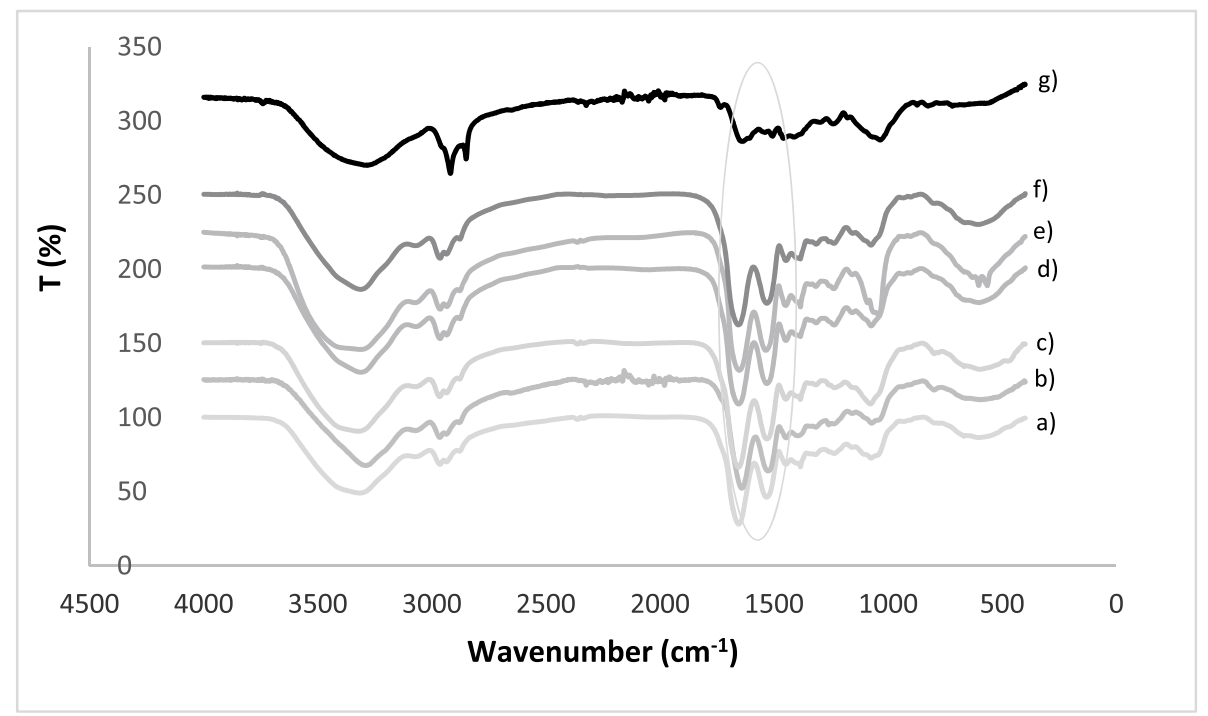

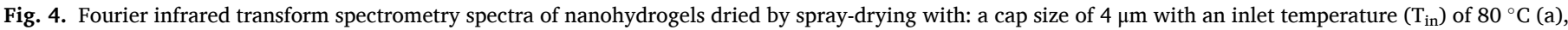
$100{ }^{\circ} \mathrm{C}$ (b) and $120{ }^{\circ} \mathrm{C}$ (c) and a cap size of $7 \mu \mathrm{m}$ with an inlet temperature $\left(\mathrm{T}_{\text {in }}\right)$ of $80{ }^{\circ} \mathrm{C}(\mathrm{d}), 100{ }^{\circ} \mathrm{C}(\mathrm{e})$ and $120{ }^{\circ} \mathrm{C}(\mathrm{f})$ and by freeze-drying (g).

properties of proteins structure. Fig. 4 shows the different FTIR patterns observed for nanohydrogels dried by spray and freeze drying.

When comparing the effect of the different inlet temperatures and cap size used to dry nanohydrogels by spray-drying it is possible to observe that the variation of these parameters did not affect the protein structure. Evaluating the nanohydrogels samples dried by spray and freeze drying is possible observe significant differences. The spectrum of nanohydrogels dried by freeze drying revealed a modification of bands at $1700-1500 \mathrm{~cm}^{-1}$, which are representative of the $\beta$-sheet structure. These results suggest that during the freeze-drying process a substantial perturbation of the proteins' secondary structure occurred (Lu, Wang, Liu, \& Ching, 2007), which was less evident in spray-dried samples. The spectra of spray-dried samples reveals that the protein structure is similar with Lf native evaluated by other authors (Luo et al., 2015).

\subsection{Scanning electron microscopy (SEM) and rehydration of samples}

SEM micrographs of the nanohydrogels dried by spray-drying and freeze-drying were collected in order to evaluate their morphology after the drying process. SEM micrographs show that after spray-drying different sizes of nanohydrogels were obtained. This can be related with the magnitude of active electrostatic forces across the cylindershape electrode where the sample was collected (Arpagaus, 2019a,b). The magnitude of the electrostatic force can result in the segregation of particles along the cylinder length and therefore in particles with different sizes (Li, Anton, Arpagaus, Belleteix, \& Vandamme, 2010). It is also important to mention that spray-dried samples are a fragile powder that during the recovering process can be easily deformed. Zhou et al. (2018) obtained similar results when dried nanogels by nano spray dryer B-90, observing the presence of agglomerates and clusters, resulting in a heterogeneous morphology sample.

It was also observed that the temperature applied to dry nanohydrogels did not affect significantly the morphology of samples as reported by Zhou, Wang, Hu, and Luo (2016) and as expected, the nozzle with higher size $(7 \mu \mathrm{m})$ reveals larger particles.

Nanohydrogels dried by freeze-drying (Fig. 5G) had a sponge-like 

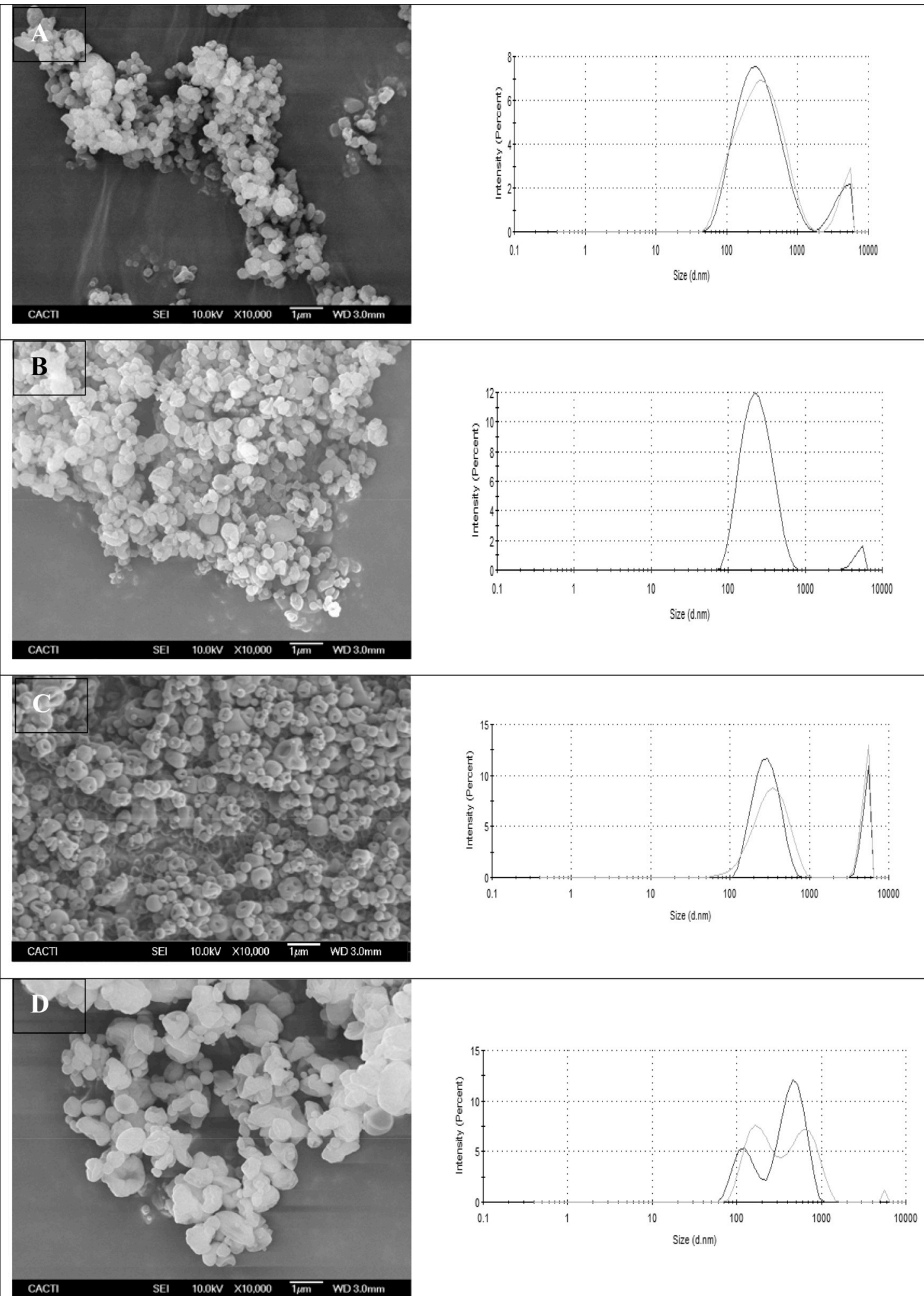

Fig. 5. SEM micrographs for nanohydrogels dried by: spray-drying with A) $\mathrm{T}_{\text {in }}$ of $80^{\circ} \mathrm{C}$ and cap size of $4 \mu \mathrm{m}$; B) $\mathrm{T}_{\text {in }}$ of $100{ }^{\circ} \mathrm{C}$ and cap size of $4 \mu \mathrm{m}$; C) $\mathrm{T}_{\text {in }}$ of $120{ }^{\circ} \mathrm{C}$ and cap size of $4 \mu \mathrm{m}$; D) $\mathrm{T}_{\text {in }}$ of $80^{\circ} \mathrm{C}$ and cap size of $7 \mu \mathrm{m}$; E) $\mathrm{T}_{\text {in }}$ of $100{ }^{\circ} \mathrm{C}$ and cap size of $\left.7 \mu \mathrm{m} ; \mathrm{F}\right) \mathrm{T}_{\text {in }}$ of $120{ }^{\circ} \mathrm{C}$ and cap size of $7 \mu \mathrm{m}$ and G) freeze-drying. The respective size distribution determined by DLS is reported for each one of the rehydrated samples.

appearance (when visually observed) and SEM image allowed identify the presence of particles with not uniform shape.

Fig. 5 shows the particle size distribution (next to photographs) obtained upon rehydration of each sample in water. The rehydration process of nanohydrogels revealed that all spray-dried samples needed more time to hydrate and a second peak was observed in the size 

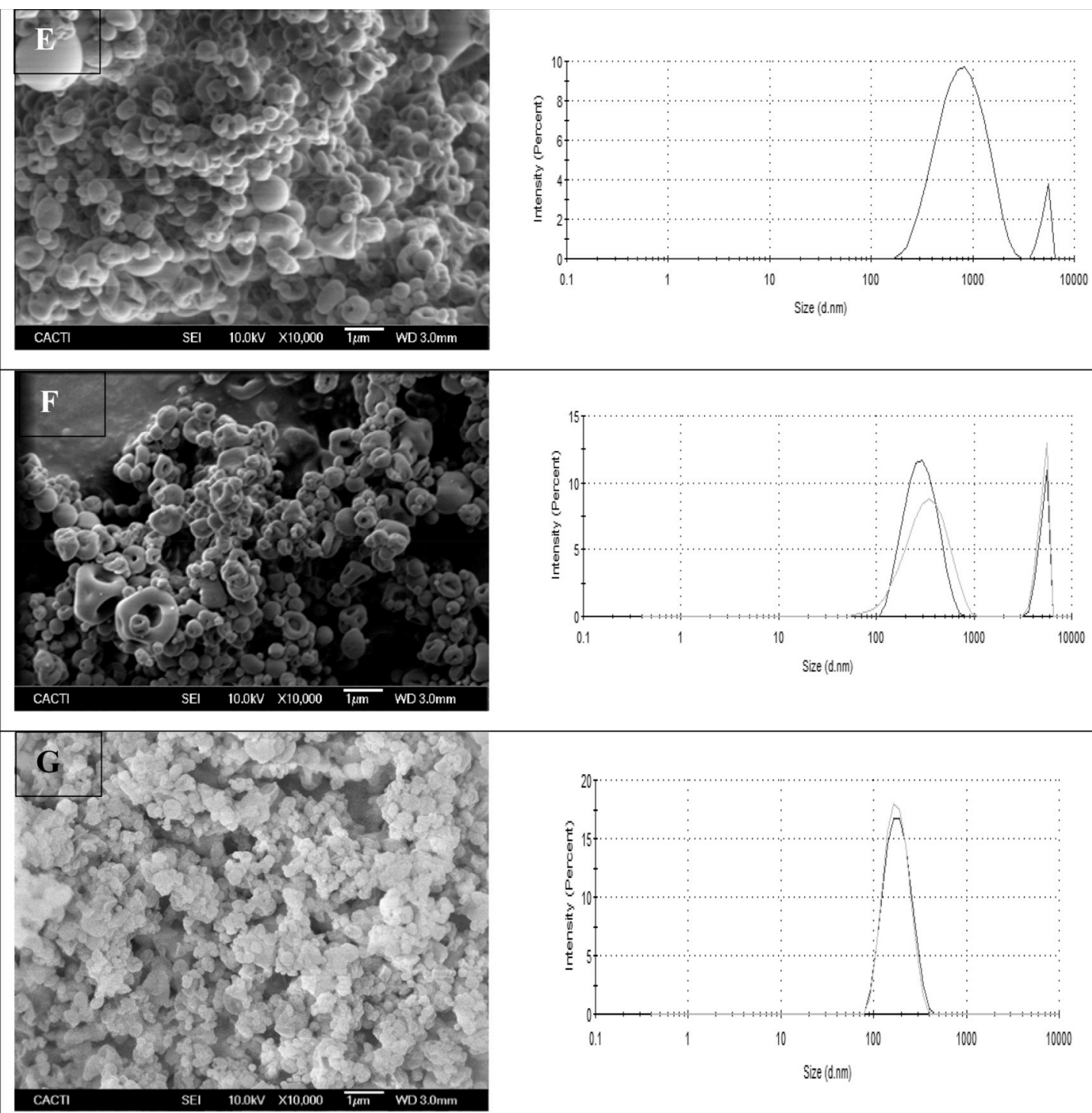

Fig. 5. (continued).

distribution, indicating the presence of agglomerates. Poor solubility can be also attributed to the outer skin formed during the drying process, possibly due to the unfolding of one to few molecules of proteins at the particle-air interface (Ghribi et al., 2015). Other authors also observed the presence of an outer skin in spray-dried lentil protein isolates (Joshi, Adhikari, Aldred, Panozzo, \& Kasapis, 2011). Freeze-dried nanohydrogels were rehydrated in a few minutes and no agglomerates were observed, as reported in a previous work (Bourbon et al., 2015). The rehydration capacity of freeze-dried samples can be accredited to less denaturation (Ghribi et al., 2015) of the nanohydrogels, as observed by the DSC analyses.

\section{Conclusions}

In this study, Lf-Gmp nanohydrogels were dried by two different methods: spray-drying and freeze drying. In spray drying process the inlet temperature $\left(80,100\right.$ and $120^{\circ} \mathrm{C}$ ) and two different sizes of cap (4 and $7 \mu \mathrm{m}$ ) were tested. Different conditions applied in spray dryer did not affect the denaturation, structure and morphology of nanohydrogels. When compared with freeze drying it was observed that freeze-dried nanohydrogels samples were more resistant to thermal degradation than spray dried samples. Moreover, freeze dried nanohydrogels revealed a structural change of proteins by FTIR. During the rehydration, nanohydrogels dried by freeze dying were fully rehydrated and no agglomerates were observed, contrarily to spray-dried nanohydrogels.

This research was extremely relevant to understand the influence of drying process in protein based nanohydrogels. Moreover, it is fundamental to understand the influence of these dying process in physical chemical properties of sensitive materials, like proteins.

\section{CRediT authorship contribution statement}

Ana I. Bourbon: Conceptualization, Methodology, Investigation, Writing - original draft. Letricia Barbosa-Pereira: Methodology, Investigation. António A. Vicente: Conceptualization, Resources, Writing - original draft, Supervision. Miguel A. Cerqueira: Conceptualization, Supervision, Writing - original draft, Supervision, Writing review \& editing. Lorenzo Pastrana: Conceptualization, Resources, Writing - original draft, Project administration.

\section{Acknowledgments}

This study was supported by the Portuguese Foundation for Science and Technology under the scope of the strategic funding of UID/BIO/ 
04469/2013 unit and COMPETE 2020 (POCI-01-0145-FEDER-006684) and BioTecNorte operation (NORTE-01-0145-FEDER-000004) funded by European Regional Development Fund under the scope of Norte2020 e Programa Operacional Regional do Norte.

\section{References}

Ameri, M., \& Maa, Y.-F. (2006). Spray drying of biopharmaceuticals: Stability and process considerations. Drying Technology, 24(6), 763-768.

Arpagaus, C. (2012). A novel laboratory-scale spray dryer to produce nanoparticles. Drying Technology, 30(10), 1113-1121.

Arpagaus, C. (2019). Chapter 3: Production of food bioactive-loaded nanoparticles by nano spray drying. In S. M. Jafari (Ed.), Nanoencapsulation of food ingredients by specialized equipment. Academic Press, Elsevier, ISBN 978-0-12-815671-1. https:// doi.org/10.1016/B978-0-12-815671-1.00004-4. Published Date: January 11.

Arpagaus, C. (2019). Pharmaceutical particle engineering via nano spray drying - process parameters and application examples on the laboratory-scale. International Journal of Medical Nano Research, 5, 026. https://doi.org/10.23937/2378-3664.1410026.

Arpagaus, C., Collenberg, A., Rütti, D., Assadpour, E., \& Jafari, S. M. (2018). Nano spray drying for encapsulation of pharmaceuticals. International Journal of Pharmaceutics, 546(1-2), 194-214. https://doi.org/10.1016/j.ijpharm.2018.05.037.

Bengoechea, C., Peinado, I., \& McClements, D. J. (2011). Formation of protein nanoparticles by controlled heat treatment of lactoferrin: Factors affecting particle characteristics. Food Hydrocolloids, 25(5), 1354-1360.

Bokkhim, H., Bansal, N., Grøndahl, L., \& Bhandari, B. (2013). Physico-chemical properties of different forms of bovine lactoferrin. Food Chemistry, 141(3), 3007-3013.

Bokkhim, H., Bansal, N., Grøndahl, L., \& Bhandari, B. (2016). Characterization of alginate-lactoferrin beads prepared by extrusion gelation method. Food Hydrocolloids, 53, 270-276.

Bourbon, A. I., Pinheiro, A. C., Carneiro-da-Cunha, M. G., Pereira, R. N., Cerqueira, M. A., \& Vicente, A. A. (2015). Development and characterization of lactoferrin-GMP nanohydrogels: Evaluation of $\mathrm{pH}$, ionic strength and temperature effect. Food Hydrocolloids, 48, 292-300. https://doi.org/10.1016/j.foodhyd.2015.02.026.

Bourbon, A. I., Cerqueira, M. A., \& Vicente, A. A. (2016). Encapsulation and controlled release of bioactive compounds in lactoferrin-glycomacropeptide nanohydrogels: Curcumin and caffeine as model compounds. Journal of Food Engineering, 180, 110-119. https://doi.org/10.1016/j.jfoodeng.2016.02.016.

Brisson, G., Britten, M., \& Pouliot, Y. (2007). Heat-induced aggregation of bovine lactoferrin at neutral pH: Effect of iron saturation. International Dairy Journal, 17(6), 617-624.

Dyvelkov, K. N., \& Sloth, J. (2014). Chapter 6 - new advances in spray-drying processes. In A. G. Gaonkar, N. Vasisht, A. R. Khare, \& R. Sobel (Eds.), Microencapsulation in the food industry (pp. 57-63). San Diego: Academic Press.

Farías, M. E., Martinez, M. J., \& Pilosof, A. M. R. (2010). Casein glycomacropeptide pHdependent self-assembly and cold gelation. International Dairy Journal, 20(2), 79-88.
Garcia-Amezquita, L. E., Welti-Chanes, J., Vergara-Balderas, F. T., \& BermúdezAguirre, D. (2016). Freeze-drying: The basic process. In B. Caballero, P. M. Finglas, \& F. Toldrá (Eds.), Encyclopedia of food and health (pp. 104-109). Oxford: Academic Press.

Ghribi, A. M., Gafsi, I. M., Blecker, C., Danthine, S., Attia, H., \& Besbes, S. (2015). Effect of drying methods on physico-chemical and functional properties of chickpea protein concentrates. Journal of Food Engineering, 165, 179-188.

González-Chávez, S. A., Arévalo-Gallegos, S., \& Rascón-Cruz, Q. (2009). Lactoferrin: Structure, function and applications. International Journal of Antimicrobial Agents, 33 (4), 301.e301-301.e308.

Hundre, S. Y., Karthik, P., \& Anandharamakrishnan, C. (2015). Effect of whey protein isolate and $\beta$-cyclodextrin wall systems on stability of microencapsulated vanillin by spray-freeze drying method. Food Chemistry, 174, 16-24.

Joshi, M., Adhikari, B., Aldred, P., Panozzo, J. F., \& Kasapis, S. (2011). Physicochemical and functional properties of lentil protein isolates prepared by different drying methods. Food Chemistry, 129(4), 1513-1522.

Lee, S. H., Heng, D., Ng, W. K., Chan, H.-K., \& Tan, R. B. H. (2011). Nano spray drying: A novel method for preparing protein nanoparticles for protein therapy. International Journal of Pharmaceutics, 403(1-2), 192-200.

Li, X., Anton, N., Arpagaus, C., Belleteix, F., \& Vandamme, T. F. (2010). Nanoparticles by spray drying using innovative new technology: The Büchi Nano Spray Dryer B-90. Journal of Controlled Release, 147(2), 304-310.

Luo, B., Liang, H., Zhang, S., Qin, X., Liu, X., Liu, W., et al. (2015). Novel lactoferrinconjugated amphiphilic poly(aminoethyl ethylene phosphate)/poly(L-lactide) copolymer nanobubbles for tumor-targeting ultrasonic imaging. International Journal of Nanomedicine, 10, 5805-5817.

Lu, J., Wang, X. J., Liu, Y. X., \& Ching, C. B. (2007). Thermal and FTIR investigation of freeze-dried protein-excipient mixtures. Journal of Thermal Analysis and Calorimetry, 89(3), 913-919.

Maltesen, M. J., \& van de Weert, M. (2008). Drying methods for protein pharmaceuticals. Drug Discovery Today: Technologies, 5(2-3), e81-e88.

Malvern, I. (2005). Size theory. In Zetasizer nano series. Worcestershire: Malvern Instruments Ltd.

Neelima, Sharma, R., Rajput, Y., \& Mann, B. (2013). Chemical and functional properties of glycomacropeptide (GMP) and its role in the detection of cheese whey adulteration in milk: A review. Dairy Science \& Technology, 93(1), 21-43.

Sheehy, P. A., Williamson, P., Sharp, J. A., Menzies, K., Lefevre, C., Digby, M., et al. (2008). Significance, origin and function of bovine milk proteins: The biological implications of manipulation or modification. Milk Proteins, 81-106.

Thomä-Worringer, C., Sørensen, J., \& López-Fandiño, R. (2006). Health effects and technological features of caseinomacropeptide. International Dairy Journal, 16(11), 1324-1333.

Zhou, M., Khen, K., Wang, T., Hu, Q., Xue, J., \& Luo, Y. (2018). Chemical crosslinking improves the gastrointestinal stability and enhances nutrient delivery potentials of egg yolk LDL/polysaccharide nanogels. Food Chemistry, 239, 840-847.

Zhou, M., Wang, T., Hu, Q., \& Luo, Y. (2016). Low density lipoprotein/pectin complex nanogels as potential oral delivery vehicles for curcumin. Food Hydrocolloids, 57, 20-29. 